\title{
Communication
}

\section{The Highly Uniform Photoresponsivity from Visible to Near IR Light in $\mathrm{Sb}_{2} \mathrm{Te}_{3}$ Flakes}

\author{
Shiu-Ming Huang ${ }^{1,2, *}$, Jai-Lung Hung ${ }^{1}$, Mitch Chou ${ }^{2,3,4}$, Chi-Yang Chen ${ }^{5}$, Fang-Chen Liu ${ }^{5}$ and Ruei-San Chen ${ }^{5}$ \\ 1 Department of Physics, National Sun Yat-sen University, Kaohsiung 80424, Taiwan; \\ Boos123boos123b@gmail.com \\ 2 Center of Crystal Research, National Sun Yat-sen University, Kaohsiung 80424, Taiwan; \\ mitch@faculty.nsysu.edu.tw \\ 3 Department of Materials and Optoelectronic Science, National Sun Yat-sen University, \\ Kaohsiung 80424, Taiwan \\ 4 Taiwan Consortium of Emergent Crystalline Materials, TCECM, National Sun Yat-sen University, \\ Kaohsiung 80424, Taiwan \\ 5 Graduate Institute of Applied Science and Technology, National Taiwan University of Science and Technology, \\ Taipei 10607, Taiwan; a0979660804@gmail.com (C.-Y.C.); ls950622@gmail.com (F.-C.L.); \\ rsc@mail.ntust.edu.tw (R.-S.C.) \\ * Correspondence: smhuang@mail.nsysu.edu.tw
}

Citation: Huang, S.-M.; Hung, J.-L.; Chou, M.; Chen, C.-Y.; Liu, F.-C.; Chen, R.-S. The Highly Uniform Photoresponsivity from Visible to Near IR Light in $\mathrm{Sb}_{2} \mathrm{Te}_{3}$ Flakes. Sensors 2021, 21, 1535. https:// doi.org/10.3390/s21041535

Academic Editors: Erwin Peiner and Pilgyu Kang

Received: 17 December 2020

Accepted: 19 February 2021

Published: 23 February 2021

Publisher's Note: MDPI stays neutral with regard to jurisdictional claims in published maps and institutional affiliations.

Copyright: (c) 2021 by the authors. Licensee MDPI, Basel, Switzerland. This article is an open access article distributed under the terms and conditions of the Creative Commons Attribution (CC BY) license (https:// creativecommons.org/licenses/by/ $4.0 /)$.

\begin{abstract}
Broadband photosensors have been widely studied in various kinds of materials. Experimental results have revealed strong wavelength-dependent photoresponses in all previous reports. This limits the potential application of broadband photosensors. Therefore, finding a wavelength-insensitive photosensor is imperative in this application. Photocurrent measurements were performed in $\mathrm{Sb}_{2} \mathrm{Te}_{3}$ flakes at various wavelengths ranging from visible to near IR light. The measured photocurrent change was insensitive to wavelengths from 300 to $1000 \mathrm{~nm}$. The observed wavelength response deviation was lower than that in all previous reports. Our results show that the corresponding energies of these photocurrent peaks are consistent with the energy difference of the density of state peaks between conduction and valence bands. This suggests that the observed photocurrent originates from these band structure peak transitions under light illumination. Contrary to the most common explanation that observed broadband photocurrent carrier is mainly from the surface state in low-dimensional materials, our experimental result suggests that bulk state band structure is the main source of the observed photocurrent and dominates the broadband photocurrent.
\end{abstract}

Keywords: $\mathrm{Sb}_{2} \mathrm{Te}_{3}$; broadband photodetector; uniform responsivity

\section{Introduction}

The interaction of light with matter has been a widely used technique for light sensors and is widely used in our daily life and scientific research. A system with higher photointeraction efficiency would lead to higher sensitivity. Therefore, there has been increasing interest in finding a material with higher photoresponsivity. The material band structure is a critical factor to finding the efficiency of the light response and light wavelength. As well as the band structure, the light penetration depth is short, so the photon interaction mainly occurs on the material surface. To enhance the photon interaction, a system with higher surface area is preferred [1-6]. In addition to the higher surface ratio, earlier studies have demonstrated that carrier mobility is one of the most critical factors for determining the light responsivity $[7,8]$. With these considerations in mind, nanostructures and low-dimensional systems with high mobility have been widely investigated [9-16]. Experimental results have revealed that most materials only show high photoresponsivity at particular wavelengths due to their specific band structure, and this limits their potential application. A broadband response along with a high photoresponsivity is important for the potential application across a wide range of wavelengths. 
A system with a linear energy-momentum band structure, such as graphene, graphenebased heterostructures, and topological materials, could satisfy these requirements and provide a high photoresponsivity over a broadband wavelength range. Many studies have demonstrated high photoresponsivity over a wide range of wavelengths in these systems. The graphene/transition metal dichalcogenide system shows an extremely fast photoresponse [17]. InGaAs shows a photoresponse for light wavelengths ranging from 400 to $16,000 \mathrm{~nm}$ [18]. However, previous reports have revealed that the photoresponses show a strong wavelength-dependent deviation in these systems [10,15,19-49]. This inhomogeneous response would limit the potential applications of these materials as broadband photosensors. The search for a system with uniform light responsivity over a wide range of wavelengths is one of the on-going topics in the field of light sensor applications. The light penetration into the material and carriers from the bulk state of the topological material might also contribute to the measured photocurrent. This might be one of the reasons behind the observed strong wavelength dependence in the previous reports [50]. To solve this problem, as well as the surface state band structure, one might take the bulk state band structure into account. We checked the bulk state band structure of BixSb(2-x)TeySe(3-y) topological materials and found that $\mathrm{Sb}_{2} \mathrm{Te}_{3}$ might be a good candidate to providing uniformity of the photocurrent over a wide range of wavelengths.

In this work, we study the photoresponse of $\mathrm{Sb}_{2} \mathrm{Te}_{3}$ flakes. Our results show that the photocurrent is linear with the light power and the applied electric voltage, and that the photoresponsivity is proportional to the conductance of the flake. According to previous reports, the photoresponsivity is stable for light wavelengths ranging from visible to nearinfrared light, and the normalized root means that the square photoresponsivity deviation is about $6 \%$, which is much lower than reported results in low-dimensional systems. The results show that the corresponding energy of the measured photocurrent peaks and dips at different light wavelengths are consistent with the energy difference of the carrier density of state peaks and dips between the conduction and valence band of $\mathrm{Sb}_{2} \mathrm{Te}_{3}$ bulk state. This result supports that the observed photoresponsivity is dominated by the carriers of the bulk state and not from the topological surface state. The low-deviated band structure of bulk state leads to the behavior of the observed uniform broadband light responsivity.

\section{Materials and Methods}

High purity elements $\mathrm{Sb}(99.995 \%)$ and Te (99.995\%) were mixed according to the stoichiometric ratio in a glove box with low oxygen and water to avoid oxidation. The mixed raw materials were put into a vacuum quartz glass tube (pressure $\sim 10^{-3}$ torr) and sealed inside the quartz glass tube. After that, the materials were melted at $750{ }^{\circ} \mathrm{C}$ for $20 \mathrm{~h}$, and then slowly cooled down to $625^{\circ} \mathrm{C}$ in $5 \mathrm{~h}$. It took another $60 \mathrm{~h}$ to cool the materials down to $565^{\circ} \mathrm{C}$ at the cooling rate $1{ }^{\circ} \mathrm{C} / \mathrm{h}$. The melting point of $\mathrm{Sb}_{2} \mathrm{Te}_{3}$ is $617^{\circ} \mathrm{C}$, so this slow cooling rate ensured that $\mathrm{Sb}_{2} \mathrm{Te}_{3}$ could be slowly crystalized. Then, it took $10 \mathrm{~h}$ to cool the materials down to room temperature. The crystallized $\mathrm{Sb}_{2} \mathrm{Te}_{3}$ was further purified and crystallized by a homemade resistance-heated floating zone furnace (RHFZ). $\mathrm{The} \mathrm{Sb}_{2} \mathrm{Te}_{3}$ was locally heated up to $617^{\circ} \mathrm{C}$ and the $\mathrm{Sb}_{2} \mathrm{Te}_{3}$ formed an interface of solid phase and liquid phase. At the same time, we slowly moved the quartz glass tube and changed the position of the solid/liquid interface. During this process, the impurities were moved with the liquid phase and were excluded from the recrystallized $\mathrm{Sb}_{2} \mathrm{Te}_{3}$. After this recrystallization process, single crystals of $\mathrm{Sb}_{2} \mathrm{Te}_{3}$ were naturally cooled down to room temperature. The as-grown crystals were cleaved along the basal plane, producing a silvery shining mirror-like surface, and then prepared for further experiments. The Raman spectrum and electron probe microanalyzer (EPMA) spectrum support that the produced crystal was $\mathrm{Sb}_{2} \mathrm{Te}_{3}$ [51]. Details of Raman spectrum and EPMA spectrum are given in Appendix $\mathrm{A} . \mathrm{Sb}_{2} \mathrm{Te}_{3}$ flakes were obtained by exfoliating bulk crystals using dicing tape and were then dispersed on the insulating $\mathrm{SiO}_{2}(300 \mathrm{~nm}) / \mathrm{n}$-Si templates with prepatterned $\mathrm{Ti} / \mathrm{Au}$ circuits. Two platinum $(\mathrm{Pt})$ metal contacts were subsequently deposited on the selected $\mathrm{Sb}_{2} \mathrm{Te}_{3}$ flakes using focused-ion beam (FIB) technique. The Chemical Abstracts 
Service (CAS) numbers of all the chemical and substrates are given in Appendix B. Details of the x-ray diffraction (XRD), Raman, EPMA, SEM, and electrical measurement system are given in Appendix C.

\section{Results and Discussion}

Figure 1 shows the XRD pattern of the produced $\mathrm{Sb}_{2} \mathrm{Te}_{3}$. The $\mathrm{Sb}_{2} \mathrm{Te}_{3}$ crystal showed sharp peaks. It revealed the Laue diffraction peaks at the c-axis. The crystal was grown on the [001] direction. The full width at half maximum (FWHM) was between 0.055 and $0.06 \mathrm{deg}$. The average crystallite size at the c-axis was about $124 \mathrm{~nm}$ and the strain was $-0.018 \%$. These results indicate that the $\mathrm{Sb}_{2} \mathrm{Te}_{3}$ was highly single crystallized. The $\mathrm{Sb}_{2} \mathrm{Te}_{3}$ powder was ground from the $\mathrm{Sb}_{2} \mathrm{Te}_{3}$ crystal. The XRD pattern of the $\mathrm{Sb}_{2} \mathrm{Te}_{3}$ powder was consistent with the Joint Committee on Powder Diffraction Standards (JCPDS) card.

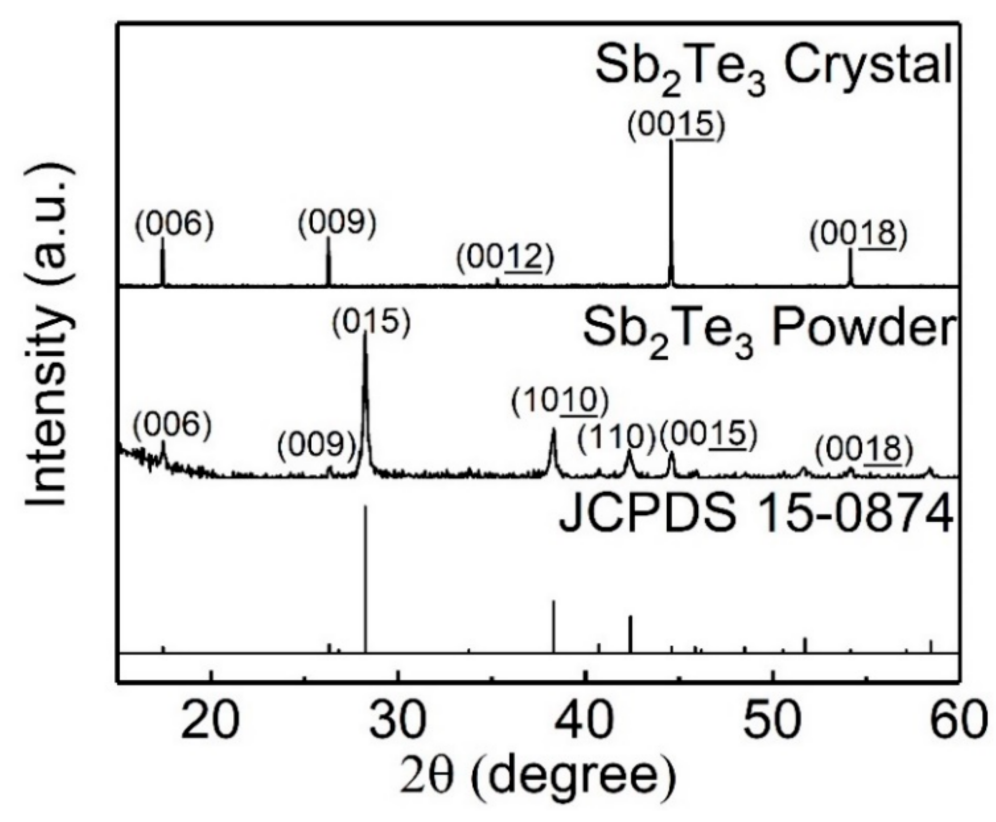

Figure 1. The X-ray diffraction (XRD) pattern of the produced $\mathrm{Sb}_{2} \mathrm{Te}_{3}$. The sharp peaks indicate that the $\mathrm{Sb}_{2} \mathrm{Te}_{3}$ is highly single crystalline. The $\mathrm{Sb}_{2} \mathrm{Te}_{3}$ powder was ground from the $\mathrm{Sb}_{2} \mathrm{Te}_{3}$ crystal. The XRD pattern of the $\mathrm{Sb}_{2} \mathrm{Te}_{3}$ powder is consistent with the JCPDS card.

Figure 2 shows the SEM image of a $\mathrm{Sb}_{2} \mathrm{Te}_{3}$ flake. It is $5 \mu \mathrm{m}$ long and $\sim 5 \mu \mathrm{m}$ wide. The thickness of a flake is determined by the atomic force microscopy; here, the flake was $260 \mathrm{~nm}$ thick (shown in the left-bottom inset of Figure 2).

The left-top inset of Figure 3 shows the linear current-voltage relationship of the flake; the conductivity is about $20.4 \mathrm{~S} / \mathrm{cm}$. The right-bottom inset of Figure 3 shows the on-off photocurrent response at different applied electric voltages under $808 \mathrm{~nm}$ light wavelength and $50 \mathrm{~mW}$ laser power. In this work, we define the photocurrent as the measured current difference between the condition with and without light illumination. The main image from Figure 3 shows that the extracted photocurrent, $I_{P}$, is linear with the applied electric voltage. These results indicate the ohmic contacts between the $\mathrm{Sb}_{2} \mathrm{Te}_{3}$ flake and $\mathrm{Pt}$ electrodes, and the metallic behavior of the $\mathrm{Sb}_{2} \mathrm{Te}_{3}$ flake.

Figure 4 shows the measured current of our $\mathrm{Sb}_{2} \mathrm{Te}_{3}$ flake under light illumination with light power ranging from 1 to $50 \mathrm{~mW}$, which corresponds to the power intensity of 40 to $2000 \mathrm{Wm}^{-2}$. The photocurrent increases with increasing light power and shows a similar power-dependent photocurrent under three different light wavelengths. The left-top inset of Figure 4 reveals the extracted photocurrent as a function of the light power at three different light wavelengths. It clearly reveals that the photocurrent varies linearly with the light power for three light wavelengths. The higher light intensity means higher photon 
interaction. The increasing amount of photon interaction will induce more excited carriers, leading to a higher photocurrent. The light intensity is not over the limit of the excited carrier number, and the measured photocurrent will be proportional to the increasing light intensity, resulting in a positive slope for the three different light wavelengths.

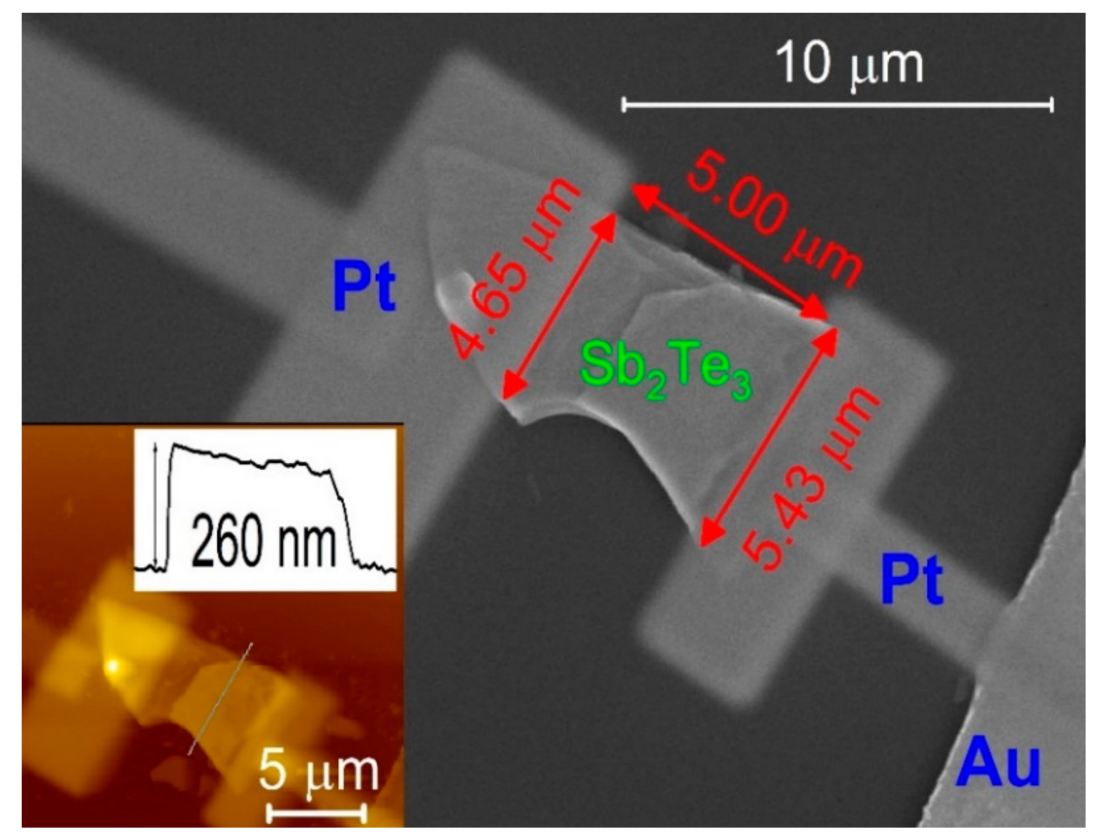

Figure 2. The $\mathrm{SEM}$ picture of the $\mathrm{Sb}_{2} \mathrm{Te}_{3}$ flake for the photocurrent experiment. Two Pt contacts were deposited on the $\mathrm{Sb}_{2} \mathrm{Te}_{3}$ flake. The left-bottom inset shows an Atomic Force Microscope (AFM) picture of the $\mathrm{Sb}_{2} \mathrm{Te}_{3}$ flake and the AFM thickness profile of the flake. The thickness is about $260 \mathrm{~nm}$.

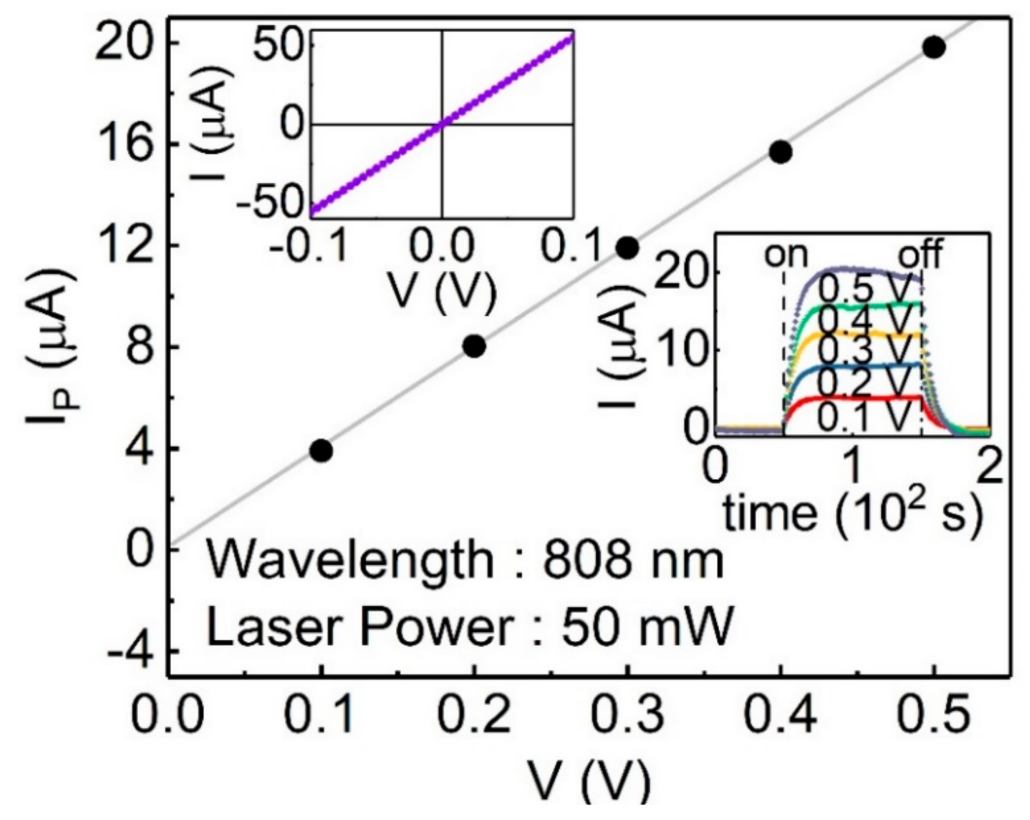

Figure 3. The left-top inset shows the linear current-voltage relationship, which indicates the ohmic contact between the $\mathrm{Sb}_{2} \mathrm{Te}_{3}$ flake and Pt electrodes. The right-bottom inset shows the measured photocurrent at different applied voltages. The main figure shows the extracted photocurrent as a function of applied voltage. The photocurrent varies linearly with the applied voltage. 


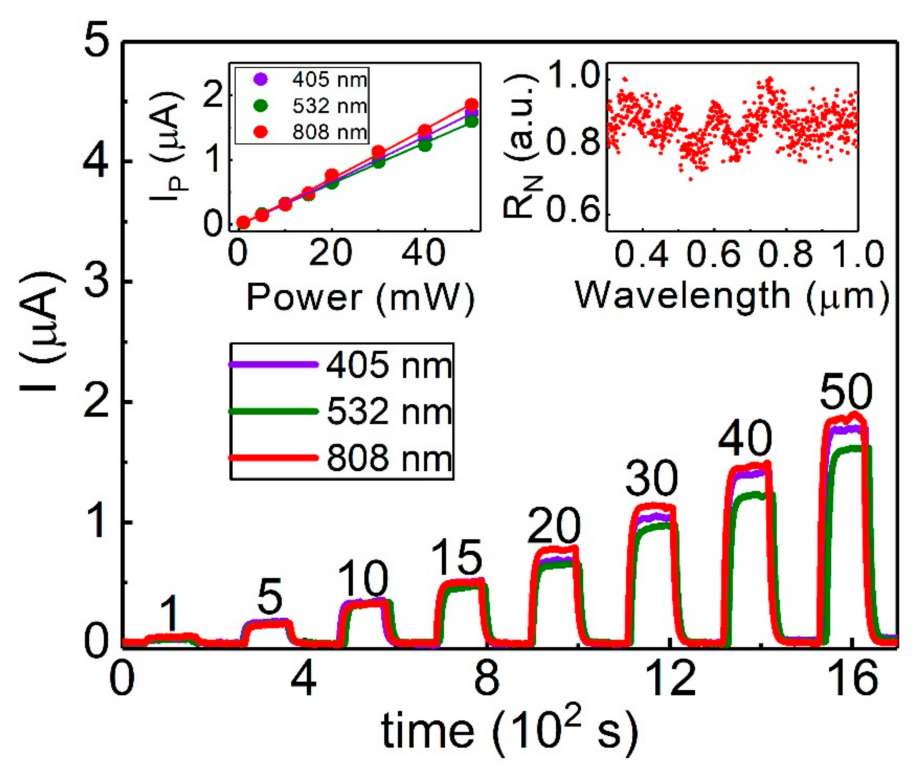

Figure 4. The photocurrent as a function of the light power at three wavelengths. The left-top inset shows that the photocurrent varies linearly with the light power at three wavelengths. The right-top inset shows that the responsivity is insensitive to wavelengths from 300 to $1000 \mathrm{~nm}$.

To further identify this characteristic in the three different wavelengths, the photocurrent is expressed as the simple power-law relation $I_{P}=\alpha P^{\beta}$, where the $\alpha$ is a constant for the wavelength of the illuminating light, $P$ is the illuminated light power on the $\mathrm{Sb}_{2} \mathrm{Te}_{3}$ flake, and $\beta$ is a constant related to the transport mechanism and the intrinsic optic characteristics. Table 1 lists $\alpha$ and $\beta$ for the three different wavelengths. The result reveals that $\beta$ is $1.03 \pm 0.02$, which indicates that the behavior of the laser power-dependent photocurrent of the system remains the same at different light wavelengths. The complex carrier scattering process might lead to the non-integer $\beta$. Our experiment shows $\beta \sim 1$, which indicates that the carrier transport process is insensitive to the extrinsic light power and interaction between excited carriers. This characteristic is more flexible and stable for a wide range of potential applications. The broadband light response has been observed in many lowdimensional systems $[10,15,19-49]$. These reports show that the observed photocurrent is strongly dependent on light wavelength, which would limit the application potential of the broadband light sensor. Advancing the findings of previous reports, our experimental results reveal that the photocurrent is weakly wavelength dependent $[10,15,19-49]$. The $\alpha$ roughly deviates by $30 \%$ at the three different wavelengths, which is much smaller than the reported values. The light power and the measured photocurrent depended upon the effective geometric area of the material. In order to quantitatively determine the performance of the $\mathrm{Sb}_{2} \mathrm{Te}_{3}$ flake under illumination, the responsivity, $R$, is calculated through the following equation:

$$
R=\frac{I_{P}}{P S},
$$

where $I_{P}, P$, and $S$ are the photocurrent, the light intensity, and the effective area, respectively. The obtained $R$ values are 38,31 , and $43 \mathrm{AW}^{-1}$ for the wavelengths of 405,532 , and $808 \mathrm{~nm}$ at a constant applied voltage of $0.1 \mathrm{~V}$. The deviation ratio is about $34 \%$.

Table 1. List of the fitting parameters of the laser power-dependent photocurrent for three light wavelengths.

\begin{tabular}{cccc}
\hline Laser Wavelength & $\mathbf{4 0 5}(\mathbf{n m})$ & $\mathbf{5 3 2}(\mathbf{n m})$ & $\mathbf{8 0 8}(\mathbf{n m})$ \\
\hline$\alpha(A / W)$ & 38 & 31 & 43 \\
$\beta$ & 1.03 & 0.99 & 1.05 \\
\hline
\end{tabular}


To further examine the photocurrent response characteristic at wide wavelength, a photocurrent spectrum measurement was performed. As shown in the top-right inset of Figure 4 , the $R$ reveals weak wavelength dependence over a range of wavelengths. The normalized root means square is used to identify the deviation level. The normalized root means square is 0.06 , which indicates a $6 \%$ deviation for the light wavelength ranging from 300 to $1000 \mathrm{~nm}$. This behavior is more stable than previously reported results in low-dimensional systems. Along with the responsivity, the responsivity stability is a critical factor for the application of broadband photosensors. Table 2 lists the reported broadband light responsivity of various kinds of materials. It shows that most of these materials reveal a large light response deviation on the broadband light wavelength. The photo deviation of the $\mathrm{Sb}_{2} \mathrm{Te}_{3}$ flake is a few orders smaller than the reported values of various materials.

Table 2. List of the wavelength range and the deviation ratio of photocurrent for reported broadband light materials.

\begin{tabular}{|c|c|c|c|}
\hline Material & Wavelength (nm) & Deviation Ratio (\%) & Reference \\
\hline $\mathrm{Sb}_{2} \mathrm{Te}_{3}$ & $300 \sim 1000$ & 34 & This work \\
\hline $\mathrm{Sb}_{2} \mathrm{Te}_{3} / \mathrm{Si} / \mathrm{Sb}_{2} \mathrm{Te}_{3}$ & $365 \sim 940$ & 98.17 & [19] \\
\hline $\mathrm{Si}$ & $350 \sim 1050$ & 109.41 & [20] \\
\hline InSe & $400 \sim 800$ & 180 & [21] \\
\hline InSe & $370 \sim 980$ & 266 & [22] \\
\hline $\mathrm{In}_{2} \mathrm{Se}_{3}$ & $250 \sim 700$ & 252 & [23] \\
\hline $\mathrm{In}_{2} \mathrm{Se}_{3}$ & $400 \sim 900$ & 104 & [24] \\
\hline AsP & $2500 \sim 8000$ & 121 & [25] \\
\hline $\mathrm{BP}$ & $300 \sim 680$ & 2449 & [26] \\
\hline $\mathrm{BP}$ & $405 \sim 940$ & 156 & [27] \\
\hline $\mathrm{MoSe}_{2}$ & $400 \sim 600$ & 87 & [28] \\
\hline $\mathrm{WSe}_{2}$ & $500 \sim 800$ & 217 & [29] \\
\hline $\mathrm{WSe}_{2}$ & $390 \sim 880$ & 70 & [30] \\
\hline $\mathrm{WS}_{2}$ & $450 \sim 650$ & 235 & [31] \\
\hline $\mathrm{MoS}_{2}$ & $400 \sim 690$ & 542 & [32] \\
\hline $\mathrm{MoS}_{2}$ & $455 \sim 850$ & 178 & {$[15]$} \\
\hline $\mathrm{PtSe}_{2}$ & $2500 \sim 10,000$ & 373 & [33] \\
\hline $\mathrm{SnS}_{2}$ & $300 \sim 700$ & 130 & {$[34]$} \\
\hline $\mathrm{SnSe}_{2}$ & $500 \sim 700$ & 286 & [35] \\
\hline Graphene & $600 \sim 9600$ & 7334 & [36] \\
\hline Graphene & $1100 \sim 1650$ & 1443 & [37] \\
\hline GaSe & $220 \sim 650$ & 165 & [38] \\
\hline GaSe & $400 \sim 800$ & 368 & [39] \\
\hline GaS & $245 \sim 610$ & 278 & [10] \\
\hline CoSe & $450 \sim 4100$ & 143 & [40] \\
\hline CoSe & $450 \sim 950$ & 132 & [40] \\
\hline $\mathrm{PbS}$ & $400 \sim 2000$ & 186 & [41] \\
\hline InGaAs & $400 \sim 16,000$ & 397 & [18] \\
\hline InGaAs & $400 \sim 1000$ & 220 & [18] \\
\hline $\mathrm{Sb}_{2} \mathrm{Se}_{3}$ & $300 \sim 1100$ & 267 & [42] \\
\hline $\mathrm{Sb}_{2} \mathrm{Se}_{3}$ & $300 \sim 1100$ & 226 & [43] \\
\hline $\mathrm{In}_{2} \mathrm{Te}_{3}$ & $350 \sim 1090$ & 129 & [44] \\
\hline $\mathrm{In}_{2} \mathrm{Te}_{3}$ & $350 \sim 1000$ & 403 & [45] \\
\hline SnTe & $405 \sim 2003$ & 120 & [46] \\
\hline SnTe & $405 \sim 808$ & 91 & [46] \\
\hline SnTe & $254 \sim 650$ & 399 & [47] \\
\hline $\mathrm{Cd}_{3} \mathrm{As}_{2}$ & $532 \sim 10,600$ & 926 & [48] \\
\hline $\mathrm{Cd}_{3} \mathrm{As}_{2}$ & $532 \sim 940$ & 140 & [48] \\
\hline $\mathrm{EuBiTe}_{3}$ & $370 \sim 1550$ & 112 & [49] \\
\hline $\mathrm{EuBiTe}_{3}$ & $370 \sim 1064$ & 110 & [49] \\
\hline
\end{tabular}

The left side of Figure 5 reveals the density of state of the $\mathrm{Sb}_{2} \mathrm{Te}_{3}$ bulk state, and it reveals several peaks at valence and conduction bands. The right side of Figure 5 shows 
the measured photoresponsivity as a function of light wavelength, and it exhibits several photocurrent peaks at different wavelengths. Our analysis shows that the corresponding energies of these measured photoresponsivity peaks and dips at different light wavelengths are consistent with the energy difference of Density of states (DOS) peaks between conduction and valence bands. This suggests that the observed photocurrent originates from these band structure peak transitions under light illumination. Contrary to most previous explanations that the observed broadband photocurrent carrier is mainly from the surface state in topological materials, our experimental result suggests that bulk state carriers are the main source of the observed photocurrent and dominate the broadband photocurrent.

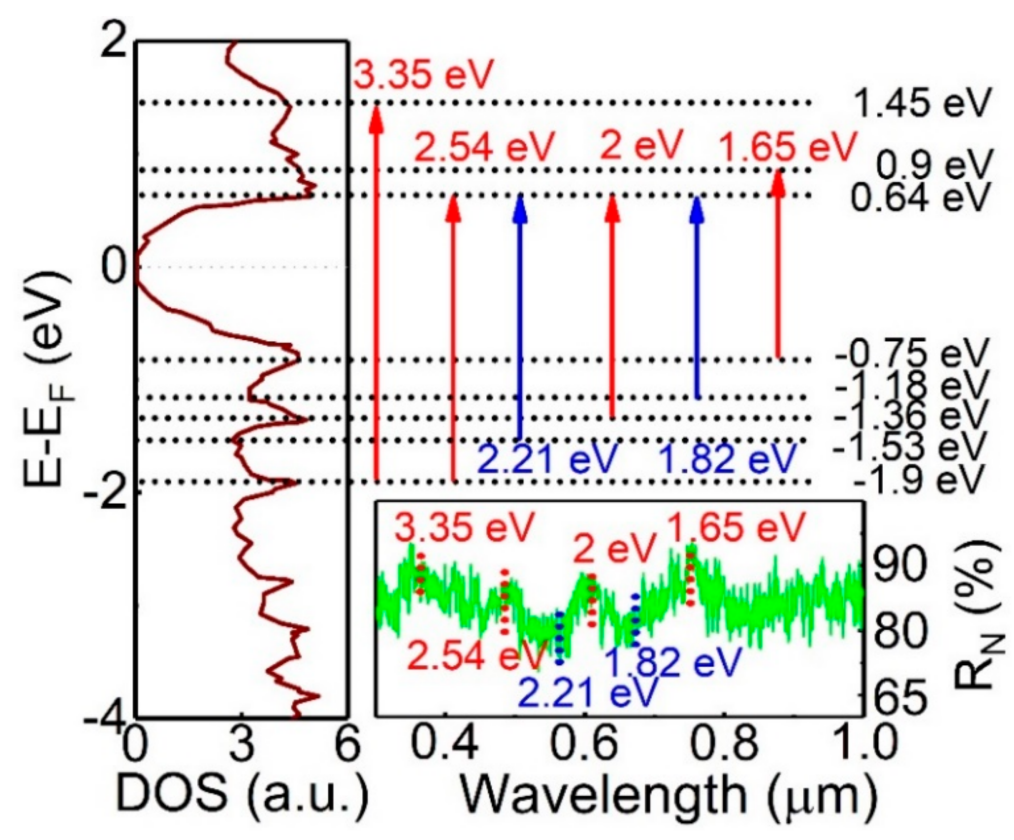

Figure 5. The left side shows the band structure of the $\mathrm{Sb}_{2} \mathrm{Te}_{3}$ bulk state. The right side shows the photocurrent as a function of light wavelength. The corresponding energies of these photocurrent peaks at different light wavelengths are consistent with the energy difference of band structure peaks between conduction and valence bands.

The photocurrent is directly related to the effective carrier mobility, which is determined by both the carriers from the bulk state and surface state. Figure 6 shows the photocurrent responsivity as a function of the conductance of the $\mathrm{Sb}_{2} \mathrm{Te}_{3}$ flakes. It shows that the photocurrent responsivity is proportional to the conductance of the $\mathrm{Sb}_{2} \mathrm{Te}_{3}$ flakes. This implies that effective conductance is a critical factor to determining the photocurrent responsivity. Detectivity, which is an important figure of merit in evaluating the ability of a photodetector to detect a weak signal, is another important index used to characterize the performance of photodetectors. The specific detectivity $\left(D^{*}\right)$ is calculated through the following equation:

$$
D^{*}=\frac{R S^{1 / 2}}{\left(2 q I_{d}\right)^{1 / 2}},
$$

where $R, S, q$, and $I_{d}$ are the responsivity, effective area of light illumination, electronic charge, and dark current, respectively. By using the experimental data, the obtained detectivity is about $2 \times 10^{9}$ Jones. As shown in the top-right inset of Figure 6 , the detectivity is almost insensitive to the flake thickness. The top-left inset of Figure 6 shows that the sensitivity is about 0.02. Our experimental results show that the detectivity and the sensitivity is insensitive to the flake thickness. However, it should be noted that the light penetration length is about $20 \mathrm{~nm}$, which is much shorter than the thickness of our $\mathrm{Sb}_{2} \mathrm{Te}_{3}$ flakes. This might be the reason behind the observed thickness-independent detectivity and sensitivity. 


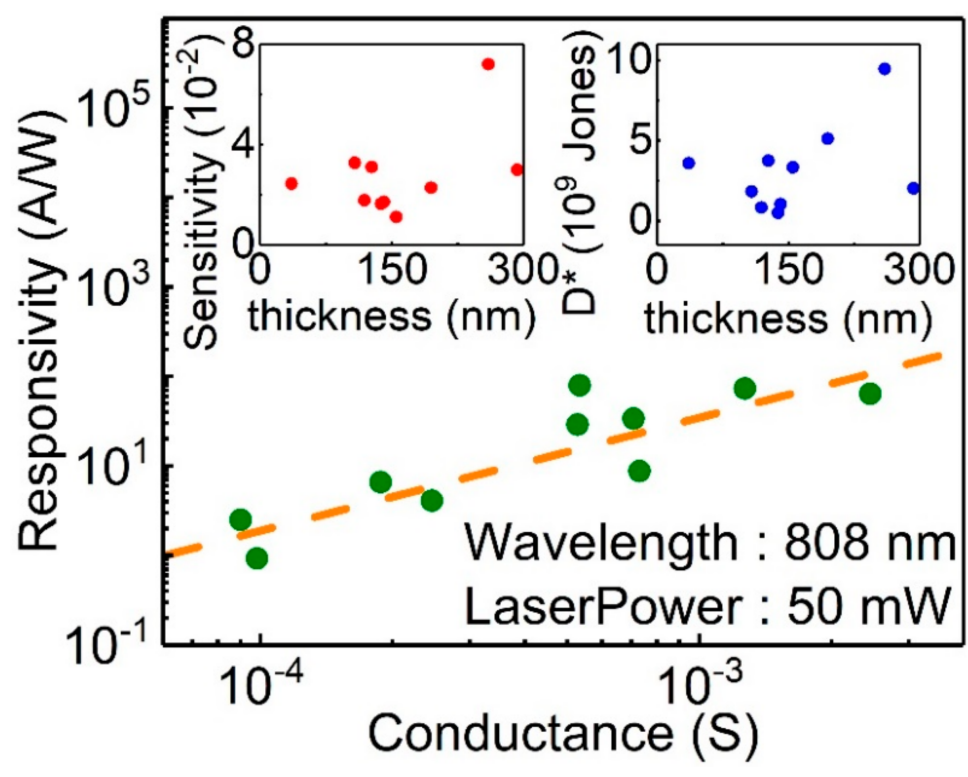

Figure 6. The responsivity is proportional to the conductance of the flake. The top-left inset shows that the responsivity is insensitive to the flake thickness. The top-right inset shows that the detectivity is insensitive to the flake thickness.

\section{Conclusions}

The photocurrent measurement was performed on $\mathrm{Sb}_{2} \mathrm{Te}_{3}$ flakes at various wavelengths ranging from visible to the near IR region. The photocurrent was observed to vary linearly with the applied electric voltage, light power, and conductance of the flakes. Advancing the findings of previous reports that the photoresponse reveals strong wavelength dependence, our measured photocurrent was insensitive to wavelengths from 300 to $1000 \mathrm{~nm}$. The wavelength response deviation was lower than that in all previously reported photoresponse materials and it has the potential to play a role in broadband photosensors. Our analysis showed that the corresponding energies of these photocurrent peaks were consistent with the energy difference of the density of state peaks between conduction and valence bands. This further suggests that the observed photocurrent originated from these band structure peak transitions under light illumination. Contrary to the most common explanation that the observed broadband photocurrent carrier is mainly from the surface state in low-dimensional materials, our experimental result suggests that the bulk state band structure is the main source of the observed photocurrent and dominates the broadband photocurrent. As well as the linear energy-momentum dispersion, one has to take the bulk state band structure into account for the broadband photo-detection material.

Author Contributions: Conceptualization: S.-M.H.; Methodology: J.-L.H.; Validation: S.-M.H. and J.-L.H.; Formal Analysis: J.-L.H.; Investigation: J.-L.H., C.-Y.C., and F.-C.L.; Resources: M.C. and R.-S.C.; Writing-Original Draft Preparation: S.-M.H.; Writing-Review and Editing: M.C., R.-S.C., and J.-L.H. All authors have read and agreed to the published version of the manuscript.

Funding: This research was funded by the Taiwan National Science Council through Grants No. MOST 106-2112-M110-002, MOST 107-2112-M-110-011-MY2, MOST 109-2112-M-110-018, and Center of Crystal Research at National Sun Yat-Sen University. S.M.H. thanks the support of short-term overseas research for scientist and technician from the Taiwan National Science Council, project Grants No. MOST 108-2918-I-110-007.

Institutional Review Board Statement: Not applicable.

Informed Consent Statement: Not applicable.

Data Availability Statement: Not applicable.

Conflicts of Interest: The authors declare no conflict of interest. 


\section{Appendix A}

The details of Raman spectrum and EPMA: The Raman spectrum shows five peaks, $\mathrm{E}_{\mathrm{g}}^{1} \mathrm{~g}: 44.40 \mathrm{~cm}^{-1}, \mathrm{E}_{\mathrm{g}}^{2}: 113.96 \mathrm{~cm}^{-1}, \mathrm{~A}_{1}(\mathrm{Te}): 126.33 \mathrm{~cm}^{-1}, \mathrm{E}^{\mathrm{H}}(\mathrm{Te}): 141.72 \mathrm{~cm}^{-1}$, and $\mathrm{A}_{1 \mathrm{~g}}^{1}$ : $165.46 \mathrm{~cm}^{-1}$. That is consistent with $\mathrm{Sb}_{2} \mathrm{Te}_{3}$ oscillation frequencies from previous reports [52,53]. EPMA shows that the ratio of $\mathrm{Sb}$ to $\mathrm{Te}$ at different portions of the single crystal ranges from $\mathrm{Sb}: \mathrm{Te}=1.95: 3$ to $2.00: 3$.

\section{Appendix B}

The CAS numbers of all the chemical and substrates: Antimony (Sb) CAS NO.744036-0; Tellurium (Te) CAS NO.13494-80-9; Silicon (Si) CAS NO.7440-21-3; Silicon dioxide $\left(\mathrm{SiO}_{2}\right)$ CAS NO.7631-86-9; Platinum (Pt) CAS NO.7440-06-4; Gold (Au) CAS NO.7440-57-5; Titanium (Ti) CAS NO.7440-32-6.

\section{Appendix C}

X-Ray Diffraction (XRD):

Equipment Model: Siemens D5000 (for powder diffraction measurement); Target: Copper $(\mathrm{Cu})$, Wavelength $\left(\lambda_{K a}\right)=0.10540598 \mathrm{~nm}$; Output Power: Voltage $=40 \mathrm{kV}$, Current $=30 \mathrm{~mA}$; Step Size: $0.05^{\circ}$; Step Time: $1.5 \mathrm{~s}$; Scan Range: $15^{\circ} \sim 60^{\circ}$.

Equipment Model: Bruker D8 (For Crystal diffraction Measurement); Target: Copper $(\mathrm{Cu})$, Wavelength $\left(\lambda_{K a}\right)=0.10540598 \mathrm{~nm}$; Output Power: Voltage $=40 \mathrm{kV}$, Current $=40 \mathrm{~mA}$; Step Size: $0.01^{\circ}$; Step Time: $0.5 \mathrm{~s}$; Scan Range: $15^{\circ} \sim 60^{\circ}$.

Raman:

Equipment Model: Micro-Raman Spectroscopy HR800; Input Laser: He-Cd laser; Wavelength: $633 \mathrm{~nm}$; Scan Range: $25 \sim 225 \mathrm{~cm}^{-1}$.

Electron Probe Microanalyzer (EPMA):

Equipment Model: JEOL JXA-8530F Field Emission Electron Probe Microanalyzer; Accelerating Voltage: $10 \mathrm{kV}$; Magnification: $5000 \times$.

Scanning Electron Microscope (SEM):

Equipment Model: FEI Quanta 3D FEG; Accelerating Voltage: $10 \mathrm{kV}$; Magnification: $3500 \times$.

Electrical Measurement System:

Equipment Model: Keithley 4200-SCS; Source Type: Voltage; 210; Voltage Range: $-0.1 \sim 0.1 \mathrm{~V}$ and0.005 V Step for Current-Voltage Measurement; Voltage: $0.1 \mathrm{~V}, 0.2 \mathrm{~V}, 0.3 \mathrm{~V}$, $0.4 \mathrm{~V}, 0.5 \mathrm{~V}$ and $1 \mathrm{~s}$ Step for Current-Time Measurement.

\section{References}

1. Chen, C.; Qiao, H.; Lin, S.; Man Luk, C.; Liu, Y.; Xu, Z.; Song, J.; Xue, Y.; Li, D.; Yuan, J.; et al. Highly responsive $M_{0} S_{2}$ photodetectors enhanced by graphene quantum dots. Sci. Rep. 2015, 5, 11830. [CrossRef] [PubMed]

2. Chen, R.S.; Wang, W.C.; Chan, C.H.; Lu, M.L.; Chen, Y.F.; Lin, H.C.; Chen, K.H.; Chen, L.C. Photoconduction efficiencies of metal oxide semiconductor nanowires: The material's inherent properties. Appl. Phys. Lett. 2013, 103, 223107. [CrossRef]

3. Konstantatos, G.; Badioli, M.; Gaudreau, L.; Osmond, J.; Bernechea, M.; de Arquer, F.P.G.; Gatti, F.; Koppens, F.H.L. Hybrid graphene-quantum dot phototransistors with ultrahigh gain. Nat. Nanotechnol. 2012, 7, 363-368. [CrossRef]

4. Roy, K.; Padmanabhan, M.; Goswami, S.; Sai, T.P.; Ramalingam, G.; Raghavan, S.; Ghosh, A. Graphene-MoS ${ }_{2}$ hybrid structures for multifunctional photoresponsive memory devices. Nat. Nanotechnol. 2013, 8, 826-830. [CrossRef] [PubMed]

5. Soci, C.; Zhang, A.; Xiang, B.; Dayeh, S.A.; Aplin, D.P.R.; Park, J.; Bao, X.Y.; Lo, Y.H.; Wang, D. ZnO Nanowire UV Photodetectors with High Internal Gain. Nano Lett. 2007, 7, 1003-1009. [CrossRef]

6. Zhang, W.; Chuu, C.-P.; Huang, J.-K.; Chen, C.-H.; Tsai, M.-L.; Chang, Y.-H.; Liang, C.-T.; Chen, Y.-Z.; Chueh, Y.-L.; He, J.-H.; et al. Ultrahigh-Gain Photodetectors Based on Atomically Thin Graphene- MoS 2 Heterostructures. Sci. Rep. 2014, 4, 3826. [CrossRef]

7. Zhang, B.Y.; Liu, T.; Meng, B.; Li, X.; Liang, G.; Hu, X.; Wang, Q.J. Broadband high photoresponse from pure monolayer graphene photodetector. Nat. Commun. 2013, 4, 1811. [CrossRef]

8. Mueller, T.; Xia, F.; Avouris, P. Graphene photodetectors for high-speed optical communications. Nat. Photonics 2010, 4, $297-301$. [CrossRef]

9. Hu, P.; Wen, Z.; Wang, L.; Tan, P.; Xiao, K. Synthesis of Few-Layer GaSe Nanosheets for High Performance Photodetectors. ACS Nano 2012, 6, 5988-5994. [CrossRef] 
10. Hu, P.; Wang, L.; Yoon, M.; Zhang, J.; Feng, W.; Wang, X.; Wen, Z.; Idrobo, J.C.; Miyamoto, Y.; Geohegan, D.B.; et al. Highly Responsive Ultrathin GaS Nanosheet Photodetectors on Rigid and Flexible Substrates. Nano Lett. 2013, 13, 1649-1654. [CrossRef]

11. Yin, Z.; Li, H.; Li, H.; Jiang, L.; Shi, Y.; Sun, Y.; Lu, G.; Zhang, Q.; Chen, X.; Zhang, H. Single-Layer MoS 2 Phototransistors. ACS Nano 2012, 6, 74-80. [CrossRef] [PubMed]

12. Furchi, M.M.; Polyushkin, D.K.; Pospischil, A.; Mueller, T. Mechanisms of Photoconductivity in Atomically Thin MoS 2 . Nano Lett. 2014, 14, 6165-6170. [CrossRef] [PubMed]

13. Tsai, D.-S.; Liu, K.-K.; Lien, D.-H.; Tsai, M.-L.; Kang, C.-F.; Lin, C.-A.; Li, L.-J.; He, J.-H. Few-Layer MoS 2 with High Broadband Photogain and Fast Optical Switching for Use in Harsh Environments. ACS Nano 2013, 7, 3905-3911. [CrossRef]

14. Zhang, W.; Huang, J.-K.; Chen, C.-H.; Chang, Y.-H.; Cheng, Y.-J.; Li, L.-J. High-Gain Phototransistors Based on a CVD MoS 2 Monolayer. Adv. Mater. 2013, 25, 3456-3461. [CrossRef]

15. Choi, W.; Cho, M.Y.; Konar, A.; Lee, J.H.; Cha, G.-B.; Hong, S.C.; Kim, S.; Kim, J.; Jena, D.; Joo, J.; et al. High-Detectivity Multilayer $\mathrm{MoS}_{2}$ Phototransistors with Spectral Response from Ultraviolet to Infrared. Adv. Mater. 2012, 24, 5832-5836. [CrossRef] [PubMed]

16. Buscema, M.; Island, J.O.; Groenendijk, D.J.; Blanter, S.I.; Steele, G.A.; van der Zant, H.S.J.; Castellanos-Gomez, A. Photocurrent generation with two-dimensional van der Waals semiconductors. Chem. Soc. Rev. 2015, 44, 3691-3718. [CrossRef] [PubMed]

17. Lv, Q.; Lv, R. Two-Dimensional Heterostructures Based on Graphene and Transition Metal Dichalcogenides: Synthesis, Transfer and Applications. Carbon 2019, 145, 240-250. [CrossRef]

18. Passmore, B.S.; Wu, J.; Manasreh, M.O.; Salamo, G.J. Dual broadband photodetector based on interband and intersubband transitions in InAs quantum dots embedded in graded InGaAs quantum wells. Appl. Phys. Lett. 2007, 91, 233508. [CrossRef]

19. Yu, X.-X.; Wang, Y.; Zhang, H.; Zhu, D.; Xiong, Y.; Zhang, W. Fabrication of a Cost Effective and Broadband Self-Powered Photodetector Based on Sb2Te3 and Silicon. Nanotechnology 2019, 30, 345202. [CrossRef] [PubMed]

20. Chander, S.; Purohit, A.; Nehra, A.; Nehra, S.P.; Dhaka, M.S. A Study on Spectral Response and External Quantum Efficiency of Mono-Crystalline Silicon Solar Cell. Int. J. Renew. Energy Res. 2015, 5, 41-44.

21. Lei, S.; Ge, L.; Najmaei, S.; George, A.; Kappera, R.; Lou, J.; Chhowalla, M.; Yamaguchi, H.; Gupta, G.; Vajtai, R.; et al. Evolution of the Electronic Band Structure and Efficient Photo-Detection in Atomic Layers of InSe. ACS Nano 2014, 8, 1263-1272. [CrossRef]

22. Yang, Z.; Jie, W.; Mak, C.-H.; Lin, S.; Lin, H.; Yang, X.; Yan, F.; Lau, S.P.; Hao, J. Wafer-Scale Synthesis of High-Quality Semiconducting Two-Dimensional Layered InSe with Broadband Photoresponse. ACS Nano 2017, 11, 4225-4236. [CrossRef]

23. Feng, W.; Gao, F.; Hu, Y.; Dai, M.; Li, H.; Wang, L.; Hu, P. High-performance and flexible photodetectors based on chemical vapor deposition grown two-dimensional $\mathrm{In}_{2} \mathrm{Se}_{3}$ nanosheets. Nanotechnology 2018, 29, 445205. [CrossRef] [PubMed]

24. Mech, R.K.; Solanke, S.V.; Mohta, N.; Rangarajan, M.; Nath, D.N. $\operatorname{In}_{2} S_{3}$ Visible/Near-IR Photodetector With Observation of Band-Edge in Spectral Response. IEEE Photonics Technol. Lett. 2019, 31, 905-908. [CrossRef]

25. Long, M.; Gao, A.; Wang, P.; Xia, H.; Ott, C.; Pan, C.; Fu, Y.; Liu, E.; Chen, X.; Lu, W.; et al. Room temperature high-detectivity mid-infrared photodetectors based on black arsenic phosphorus. Sci. Adv. 2017, 3, e1700589. [CrossRef] [PubMed]

26. Wu, J.; Koon, G.K.W.; Xiang, D.; Han, C.; Toh, C.T.; Kulkarni, E.S.; Verzhbitskiy, I.; Carvalho, A.; Rodin, A.S.; Koenig, S.P.; et al. Colossal Ultraviolet Photoresponsivity of Few-Layer Black Phosphorus. ACS Nano 2015, 9, 8070-8077. [CrossRef]

27. Buscema, M.; Groenendijk, D.J.; Blanter, S.I.; Steele, G.A.; van der Zant, H.S.J.; Castellanos-Gomez, A. Fast and Broadband Photoresponse of Few-Layer Black Phosphorus Field-Effect Transistors. Nano Lett. 2014, 14, 3347-3352. [CrossRef]

28. Patel, A.B.; Chauhan, P.; Machhi, H.K.; Narayan, S.; Sumesh, C.K.; Patel, K.D.; Soni, S.S.; Jha, P.K.; Solanki, G.K.; Pathak, V.M. Transferrable thin film of ultrasonically exfoliated $\mathrm{MoSe}_{2}$ nanocrystals for efficient visible-light photodetector. Phys. E Low-dimensional Syst. 2020, 119, 114019. [CrossRef]

29. Zhang, W.; Chiu, M.-H.; Chen, C.-H.; Chen, W.; Li, L.-J.; Wee, A.T.S. Role of Metal Contacts in High-Performance Phototransistors Based on $\mathrm{WS}_{2}$ Monolayers. ACS Nano 2014, 8, 8653-8661. [CrossRef]

30. Pataniya, P.; Zankat, C.K.; Tannarana, M.; Sumesh, C.K.; Narayan, S.; Solanki, G.K.; Patel, K.D.; Pathak, V.M.; Jha, P.K. Paper-Based Flexible Photodetector Functionalized by WSe 2 Nanodots. ACS Appl. Nano Mater. 2019, 2, 2758-2766. [CrossRef]

31. Perea-López, N.; Elías, A.L.; Berkdemir, A.; Castro-Beltran, A.; Gutiérrez, H.R.; Feng, S.; Lv, R.; Hayashi, T.; López-Urías, F.; Ghosh, S.; et al. Photosensor Device Based on Few-Layered $W_{2}$ Films. Adv. Funct. Mater. 2013, 23, 5511-5517. [CrossRef]

32. Lopez-Sanchez, O.; Lembke, D.; Kayci, M.; Radenovic, A.; Kis, A. Ultrasensitive photodetectors based on monolayer MoS 2 . Nat. Nanotechnol. 2013, 8, 497-501. [CrossRef] [PubMed]

33. Yu, X.; Yu, P.; Wu, D.; Singh, B.; Zeng, Q.; Lin, H.; Zhou, W.; Lin, J.; Suenaga, K.; Liu, Z.; et al. Atomically thin noble metal dichalcogenide: A broadband mid-infrared semiconductor. Nat. Commun. 2018, 9, 1545. [CrossRef]

34. Tao, Y.; Wu, X.; Wang, W.; Wang, J. Flexible photodetector from ultraviolet to near infrared based on a $S n S_{2}$ nanosheet microsphere film. J. Mater. Chem. C 2015, 3, 1347-1353. [CrossRef]

35. Zhou, X.; Gan, L.; Tian, W.; Zhang, Q.; Jin, S.; Li, H.; Bando, Y.; Golberg, D.; Zhai, T. Ultrathin $S_{n S e_{2}}$ Flakes Grown by Chemical Vapor Deposition for High-Performance Photodetectors. Adv. Mater. 2015, 27, 8035-8041. [CrossRef] [PubMed]

36. Ogawa, S.; Shimatani, M.; Fukushima, S.; Okuda, S.; Kanai, Y.; Ono, T.; Matsumoto, K. Broadband photoresponse of graphene photodetector from visible to long-wavelength infrared wavelengths. Opt. Eng. 2019, 58, 057106. [CrossRef]

37. Unsuree, N.; Selvi, H.; Crabb, M.G.; Alanis, J.A.; Parkinson, P.; Echtermeyer, T.J. Visible and infrared photocurrent enhancement in a graphene-silicon Schottky photodetector through surface-states and electric field engineering. 2D Mater. 2019, 6, 041004. [CrossRef] 
38. Sorifi, S.; Moun, M.; Kaushik, S.; Singh, R. High-Temperature Performance of a GaSe Nanosheet-Based Broadband Photodetector. ACS Appl. Electron. Mater. 2020, 2, 670-676. [CrossRef]

39. Cao, Y.; Cai, K.; Hu, P.; Zhao, L.; Yan, T.; Luo, W.; Zhang, X.; Wu, X.; Wang, K.; Zheng, H. Strong enhancement of photoresponsivity with shrinking the electrodes spacing in few layer GaSe photodetectors. Sci. Rep. 2015, 5, 8130. [CrossRef]

40. Liang, F.; Wang, C.; Luo, C.; Xia, Y.; Wang, Y.; Xu, M.; Wang, H.; Wang, T.; Zhu, Y.; Wu, P.; et al. Ferromagnetic CoSe broadband photodetector at room temperature. Nanotechnology 2020, 31, 374002. [CrossRef] [PubMed]

41. Lee, J.W.; Kim, D.Y.; Baek, S.; Yu, H.; So, F. Inorganic UV-Visible-SWIR Broadband Photodetector Based on Monodisperse PbS Nanocrystals. Small 2016, 12, 1328-1333. [CrossRef]

42. Chen, S.; Shehzad, K.; Qiao, X.; Luo, X.; Liu, X.; Zhang, Y.; Zhang, X.; Xu, Y.; Fan, X. A high performance broadband photodetector based on $\left(S n_{x} S b_{1-x}\right) S e_{3}$ nanorods with enhanced electrical conductivity. J. Mater. Chem. C 2018, 6, 11078-11085. [CrossRef]

43. Hasan, M.R.; Arinze, E.S.; Singh, A.K.; Oleshko, V.P.; Guo, S.; Rani, A.; Cheng, Y.; Kalish, I.; Zaghloul, M.E.; Rao, M.V.; et al. An Antimony Selenide Molecular Ink for Flexible Broadband Photodetectors. Adv. Electron. Mater. 2016, 2, 1600182. [CrossRef]

44. Wang, Z.; Safdar, M.; Jiang, C.; He, J. High-Performance UV-Visible-NIR Broad Spectral Photodetectors Based on OneDimensional $\mathrm{In}_{2} \mathrm{Te}_{3}$ Nanostructures. Nano Lett. 2012, 12, 4715-4721. [CrossRef]

45. Yan, S.; Zhou, L.; Shi, Y.; Wang, B.; Wang, J.; Xu, X. Solvothermal Synthesis of Indium Telluride Nanowires and Its Photoelectrical Property. J. Nanosci. Nanotechnol. 2015, 15. [CrossRef] [PubMed]

46. Jiang, T.; Zang, Y.; Sun, H.; Zheng, X.; Liu, Y.; Gong, Y.; Fang, L.; Cheng, X.; He, K. Broadband High-Responsivity Photodetectors Based on Large-Scale Topological Crystalline Insulator SnTe Ultrathin Film Grown by Molecular Beam Epitaxy. Adv. Opt. Mater. 2017, 5, 1600727. [CrossRef]

47. Yang, J.; Yu, W.; Pan, Z.; Yu, Q.; Yin, Q.; Guo, L.; Zhao, Y.; Sun, T.; Bao, Q.; Zhang, K. Ultra-Broadband Flexible Photodetector Based on Topological Crystalline Insulator SnTe with High Responsivity. Small 2018, 14, 1802598. [CrossRef] [PubMed]

48. Wang, Q.; Li, C.-Z.; Ge, S.; Li, J.-G.; Lu, W.; Lai, J.; Liu, X.; Ma, J.; Yu, D.-P.; Liao, Z.-M.; et al. Ultrafast Broadband Photodetectors Based on Three-Dimensional Dirac Semimetal $C d_{3} A s_{2}$. Nano Lett. 2017, 17, 834-841. [CrossRef]

49. Niu, Y.; Wang, B.; Chen, J.; Wu, D. Ultra-broadband and highly responsive photodetectors based on a novel EuBiTe 3 flake material at room temperature. J. Mater. Chem. C 2018, 6, 713-716. [CrossRef]

50. Zhang, H.; Zhang, X.; Liu, C.; Lee, S.-T.; Jie, J. High-Responsivity, High-Detectivity, Ultrafast Topological Insulator Bi2Se3/Silicon Heterostructure Broadband Photodetectors. ACS Nano 2016, 10, 5113-5122. [CrossRef]

51. Jian, H.-L. Investigation of Crystal Properties of Topological Insulator $\mathrm{Bi}_{(\mathrm{x})} \mathrm{Sb}_{(2-\mathrm{X})} \mathrm{Te}_{3}$ by Melting Growth Method. Master's Thesis, National Sun Yat-Sen University, Kaohsiung, Taiwan, 4 September 2018.

52. Shahil, K.M.F.; Hossain, M.Z.; Goyal, V.; Balandin, A.A. Micro-Raman Spectroscopy of Mechanically Exfoliated Few-Quintuple Layers of Bi2Te3, Bi2Se3, and Sb2Te3 Materials. J. Appl. Phys. 2012, 111, 054305. [CrossRef]

53. Zybala, R.; Mars, K.; Mikuła, A.; Boguslawski, J.; Sobon, G.; Sotor, J.; Schmidt, M.; Kaszyca, K.; Chmielewski, M.; Ciupinski, L.; et al. Synthesis and Characterization of Antimony Telluride for Thermoelectric and Optoelectronic Applications. Arch. Metall. Mater. 2017, 62. [CrossRef] 